\title{
SITUATIONAL APPROACHES TO LEADING PEOPLE IN THE FIRE SERVICES
}

\section{Mária Hudáková}

University of Žilina, Faculty of special engineering,Department of crisis management, Ul.1.mája 32, 01026 Žilina, Slovakia

\section{Jozef Svetlík}

University of Žilina, Faculty of special engineering, Department of fire management, Ul.1.mája 32, 01026 Žilina, Slovakia

\section{() MESTE NGO}

JEL classification: L, L59, L89

\begin{abstract}
Summary:
Current knowledge about the management of people is a result of long-term observation of the proceedings and conduct of people in leadership as well as in subordinate positions. There are different views on the way and methods of on which are defined the different styles of leadership. The paper provides an analysis of leadership approaches, which shows that the leaders in the fire service is the most effective situational approach. This approach is strongly influenced by the leadership situation in which the manager operates. Therefore, its behavior has changed to satisfy the requirements of the situation. The mission leader should be to develop mature team members to be able to effectively achieve organizational goals. In connection with the need to apply situational leadership approach is necessary to provide primarily personal qualities leading to significantly contribute to the ability to influence others head. It is actually a set of subjective factors that make up a qualification leading to fire departments and other prerequisites for the implementation of the tasks.
\end{abstract}

\section{Keywords:}

crisis manager, people management, crisis situation, the commander of the intervention, fire unit

The address of the corresponding author: Mária Hudáková 拝=゙maria.hudakova@fsi.uniza.sk

\section{CRISIS MANAGER}

The crisis manager is ready to identify, analyze and evaluate potential risks, coordinate the preparation of contingency plans in the case of a 
crisis, propose emergency measures and procedures to effectively manage their course, effectively coordinate personnel, communicate with employees, the public and especially the media.

Consequently, the crisis manager is ready to address a crisis in the company by performing the following actions:

- decides on the tasks, resources and specific measures required to solve problems quickly, in order to eliminate the consequences of the crisis, monitor and evaluate the situation,

- ensures functioning of the crisis information system, providing effective communication, not only for the team but also to the public,

- manages and coordinates all the activities involved in the crisis, and supports the psychological resilience of the team.

It is clear that the crisis manager's focus of work is decision making, which is important for rapid assessment of the crisis and guiding the team in the effort to reach equilibrium and better protection and security. Appropriate decisions in dealing with corporate crises are based on the available information and its quality. Increasing stress narrows attention and causes the oversight or underestimation of important information. Unclear information and pressure on its fast processing can lead to misinterpretation. Therefore, the crisis manager's decision-making ability is the main source of success when dealing with corporate crises.

The output of the crisis manager's work is influenced by his knowledge, abilities, goals, how much effort they are willing to spend to achieve their objectives, and what their personal and moral qualities are. It is actually a set of subjective factors and other prerequisites for the implementation of the tasks, that form a skilled crisis manager for example:

- Expert knowledge improves the professional crisis manager's readiness to work and it is a result of general and higher education. This includes for example: the knowledge of work processes, work organization, knowledge of law, regulations, standards and the ability to use them properly.
- Life and work experience emphasizes the practice of the manager and how they have gained their experience. They have an important role in crisis management in helping to develop and test organizational skills, management, and teamwork. To successfully manage a crisis, the crisis manager should have some experience with business solutions of the crisis.

- Work efficiency refers to the degree of physical, mental and emotional fitness of the manager in overcoming stress and stress situations. Mental readiness to solve unexpected problems and preparedness allows the crisis manager to cope with negatives, and eliminate stress. High psychological stress in times of crisis can trigger a reaction to seek escape and panic.

- Personal characteristics of the crisis manager positively affecting teamwork are mainly patience, tolerance, sensitivity, emphaty, precision, decisiveness, purposefulness, consistency, ability to work under the conditions of risk. The crisis manager must be able to think independently, flexibly, and know how to apply the results in a particular activity.

\section{ANALYSIS OF APPROACHES TO LEADING PEOPLE IN THE FIRE DEPARTMENT}

An important role in crisis management plays the aforementioned personality of the crisis manager, his character, knowledge, experience, skills and abilities, but also the ability to effectively lead a crisis team.

Team crisis management is one of the key joint actions of company management. In essence the process of influencing people, in which the executive, with the use of their power, strives for voluntary and willing participation of subordinates to achieve group objectives, and thereby meet their needs. Management is focused on people, affecting their behavior, in order to achieve organizational objectives. In a crisis - incident, the team is represented by a fire brigade unit.

An effective leader has typical personality characteristics that predispose them to fulfill leadership roles. It is a management approach 
based on a larger number of personal qualities. The representatives of this approach were examined for important leadership qualities, looking for those that made them successful leaders. Generally, these qualities can be divided into the following groups(Míka, 2007):

- physical properties (appearance, weight, height, age, etc.),

- capabilities (knowledge, intelligence, eloquence, etc.),

- personal characteristics (courage, dominance, confidence, charisma, etc.).

The representatives of this approach came to a conclusion that most of these qualities are inherited, a successful leader is thus born, so they must be looked for. Newer approaches, respecting the importance of personal qualities (eg, transformational leadership theory), focus on how these properties should be gained.

The application of the approach based on the qualities of the leader has proved difficult in practice. Therefore, more attention is focused on on the behavior of the leader and the related styles of behavior. It is a style of management, ensuring an efficient and effective fulfillment of performance objectives.

Leading and management of a fire brigade unit is an important role of the commander. For the purposes of fulfilling the commander's duties, the command may be divided into:

- Leading and management of direct subordinates,

- leading and management coordination of all divisions of the integrated rescue system and the coordination of their resources,

- implementation of cooperation with other parties and individuals involved in the intervention.

A leadership style can be characterized as a typical way of behavior of the leader, a steady way for exercising the management of subordinates.

In the process of crisis management, during the phase of corporate crisis prevention, the crisis manager should be able to readily identify the outbreak of a crisis, which may be various corporate weaknesses, and flexibly propose options for the elimination of the crisis. It is a common situation in which, in the terms of team management, the manager uses their own style (ie democratic) with the emphasis on:

- The ability to predict future trends, based on the present situation, to see tendencies that are already contained in the present.

- The ability of a wider than average perception and using intuition.

- Integrate predicted and actual changes, and combine them to deduce the future.

Democratic style - characterized by active bidirectional communication between managers and subordinates, and the innovative work activity on the part of the subordinates.

At the time of solving a company crisis, demands on emergency managers are being increased, because such situations usually require a directive leader who can lead the team, and maintain discipline and cohesion. Their executive power is authority that they must gain and continually strengthen. Sometimes, it is recommended that the crisis manager should combine the directive approach with the democratic one. The essence of this combination is that every team and every individual has their designated goal, which is derived from the business objectives and this goal corresponds with the capabilities of the team or individual.(Buganová, 2010)

In the case of rescue units, the directive style of management is automatically used. The commander is responsible for the intervention and that the subordinates (firefighters) fulfill their commands. The objective of rescue and intervention activities is to protect lives.

Head of intervention (commander):

- Is responsible for organizing the activities of the fire brigades and the use of their material resources at the scene and for the principles of health and safety at work.

- Respects the principles of command priority.

- The commander may order persons to leave the scene of the accident, if their presence in not necessary or required..

- Manages interventions by the deployment of appropriate numbers of forces and means of fire brigades. 
If the unit does not interfere, it is possible to implement some elements of the democratic management style in the form of a degree of freedom for the subordinates.

The characteristics of the directive management style are:

- performs strongly authoritative,

- has decision-making and commanding powers,

- does not tolerate opposition and is willing to use sanctions,

- decisions are made clearly, quickly, concisely, without any efforts to provide significant reasoning,

- not open to criticism, defend their beliefs, and forces its adoption,

- tends to show their superiority always and everywhere.

If the crisis manager has natural authority, they can lead the team in their own style, which is determined by a unique combination of personal qualities. Their success in working with people is subject to perfect knowledge of motives and motivation mechanisms. The expected result of the work of the individuals inside a team is dependent on their motivation.

In the case of fire it is ideal when the commander has natural authority. The success of the intervention often depends on his decisions so they can directly affect the life of the involved persons. Confidence in the decisions of the commander is therefore necessary, and it is not desirable if the commander does not have natural authority and confidence of his subordinate staff.

\section{SITUATIONAL APPROACH}

Practical experience shows that the efficiency of leadership behavior does not only depend on the management style applied. There are emerging requirements for more flexible management styles that would better match the nature of the task-level subordinates and other important situational factors. Current changes in the external and internal environment and the need for the manager to respond flexibly requires a flexible management style adaptation. It this case, we can talk about situational approaches, which do not reject any particular management style, but rather emphasize which management style will be effective, depending on the situation. The situational approach may be expressed as the union of efficient leadership with the actual situation. Based on this, leadership is strongly affected by the situation in which it is being applied.

In this case, the situation is meant as a mutual relation of external and internal conditions of the assignment, manager's personality, level and motivation of subordinates, as well as the leadership style at senior levels in the organization.(Vel'as, 2011)

Situational leadership theories assume that:

- a natural leader does not exist

- everything depends on the specific situation that may determine who is suitable for the leader position at the moment

- the situation determines what management style is effective.

There are a variety of situational leadership theories, for example(Majtán, 2008):

1. The theory of variable behavior.

2. Fiedler's theory of effective leadership.

3. Theory of way - objective relation.

4. Hersey and Blanchard theory.

\subsection{The theory of variable behavior}

The theory of variable behavior, recommends that leaders, managers differentiate their behavior and leadership style appropriately to the particular situation, respectively. circumstances. The most important factors that can affect the management style are:

- managerial strength of personality manager's value system, trust in their subordinates, tendency to a particular leadership style, a sense of security in some situations,

- power of subordinates who can affect the behavior of the leader (eg, willingness to take responsibility, knowledge and experience, etc.),

- situational strenghts, such as the values and traditions of the organization, the work effectiveness of the subordinates as a whole, the nature of the problem, the possibility of safe responsibility delegation, time pressure. 


\subsection{Fiedler's theory of effective leadership}

Fiedler's theory of effective leadership is based on the assumption that people become leaders, not only because they have the required personal qualities, but also due to the action of various situational factors, as well as the relationship between the leader and group members. The critical aspects of situational leadership are:

- power of position (function), i.e. power in the organization - leader with obvious and significant power can persuade co-workers easier,

structure of tasks - when tasks are clear, it is significantly easier to control the work of subordinates and designate personal responsibilities,

- relationship between the leader and group members - this dimension is considered the most important as it affects popularity, trust and willingness of the subordinates to follow the leader.
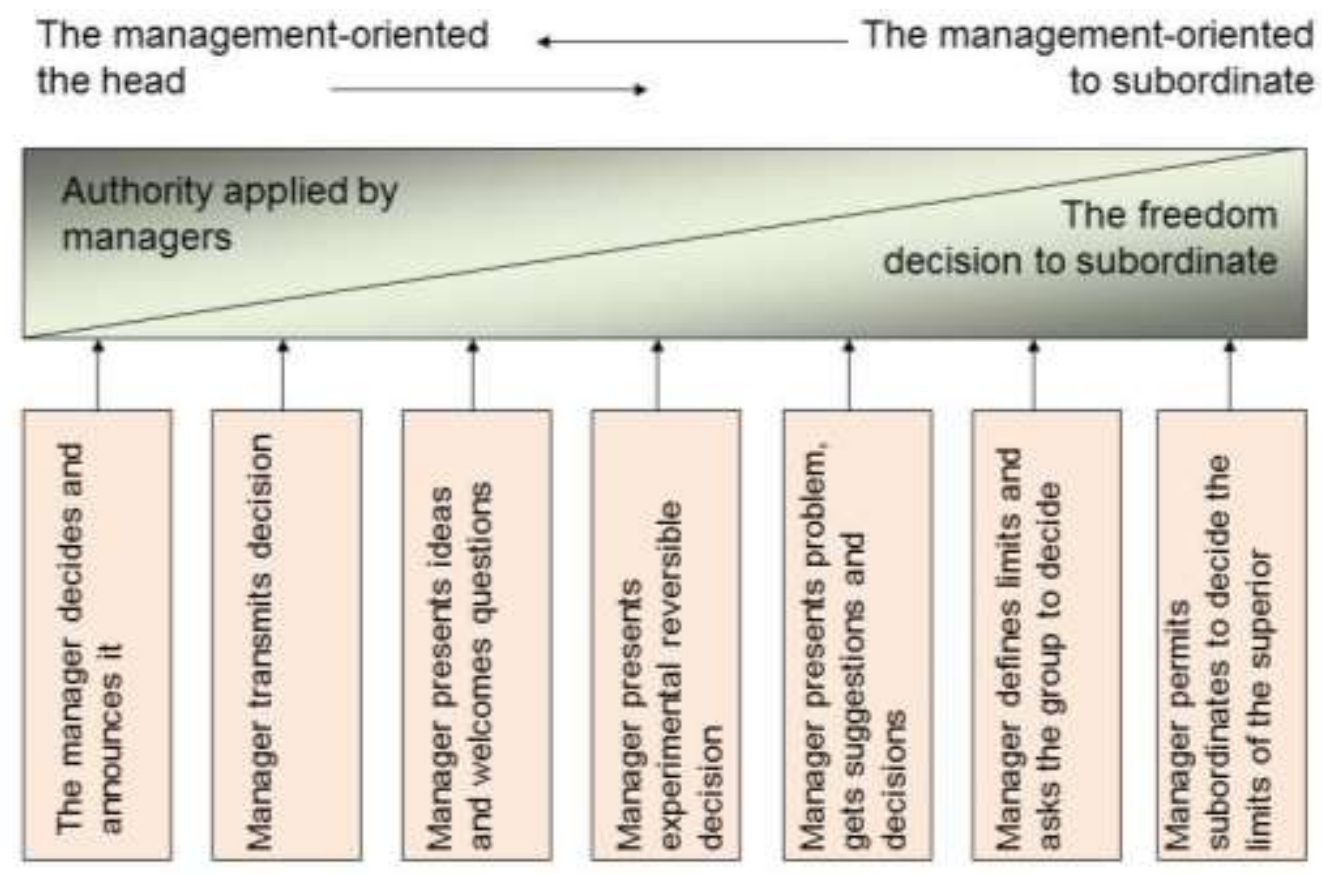

Fig. 1 Behaviour continuum in persons management (Majtán, 2008)

\subsection{Theory of way - objective relation}

The essence of the of way - objective relation theory lies in the fact that the leader motivates subordinates by clarifying the path to personal success as a result of the achievement of the set objectives. The theory assumes that the leader's behavior is acceptable to the extent that corresponds with the level of the subordinates" satisfaction. Leaders must operate in various environments, which differ structurally. Therefore, their behavior has to change to satisfy the requirements of the situation. In this case, the effectiveness of leadership is achieved in accordance with the situation, so the leader can apply multiple styles of leadership (the need for the leader's flexibility). In theory, situational factors cover the following important aspects:
- characteristics of employees (needs, selfconfidence, ability),

- environment factors (job, remuneration, personal relations).

\subsection{Hersey and Blanchard theory}

Paul Hersey and Kenneth Blanchard introduced a new variable - maturity. The degree of maturity is expressed by the readiness to perform a task. The leader should choose a management style depending on the maturity of the subordinates. The leader's behavior can be described in two dimensions:

- supportive behavior (which is the same as respect for people),

- directive behavior (which corresponds to the structure of, or orientation for the role). 
The main objective of the leader's work is the development of maturity in the team. The team is then able to achieve organization goals. Even for this theory it is possible to create a diagram to define the four leadership styles, see Fig. 2:
- ordering,

- coaching,

- supporting,

- delegating.

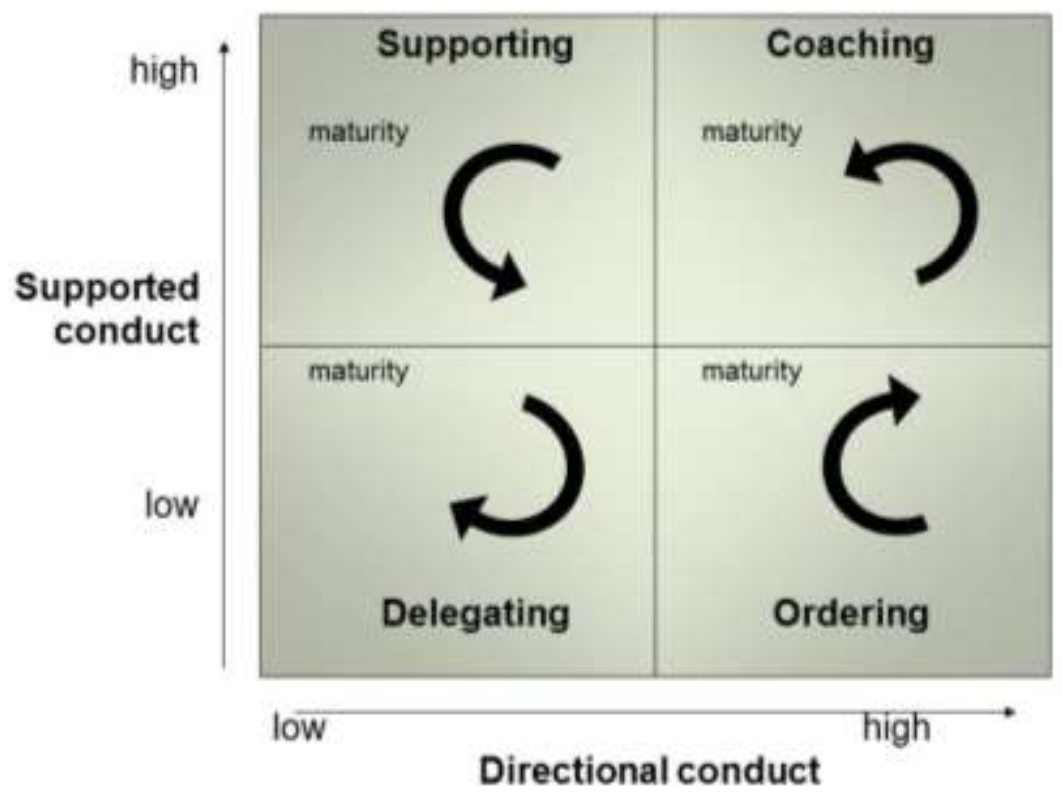

Fig. 2 Situational management (Majtán, 2008)

Table. 1 provides a brief summary of the three most useful (popular) theories of leadership characteristics, highlighting the importance of the situation.

Table 1. Comparison of situational leadership theories (Donnelly, Gibson, \& Ivancevich, 1997)

\begin{tabular}{|c|c|c|c|}
\hline Point of comparison & $\begin{array}{l}\text { Fiedler's theory of } \\
\text { effective leadership }\end{array}$ & $\begin{array}{l}\text { Theory of way - } \\
\text { objectives relation }\end{array}$ & $\begin{array}{l}\text { Hersey and } \\
\text { Blanchard } \\
\text { theory }\end{array}$ \\
\hline The basic idea & $\begin{array}{l}\text { There is no best style. } \\
\text { The success of the } \\
\text { leader is determined } \\
\text { by the interaction of } \\
\text { the environment and } \\
\text { the characteristics of } \\
\text { his personality. }\end{array}$ & $\begin{array}{c}\text { The most successful } \\
\text { leaders are those who } \\
\text { increase subordinate } \\
\text { motivation by } \\
\text { identifying and } \\
\text { explaining ways to } \\
\text { effective performance. }\end{array}$ & $\begin{array}{l}\text { Successful managers } \\
\text { adapt their style to the } \\
\text { situation requirements. }\end{array}$ \\
\hline $\begin{array}{l}\text { Leadership style } \\
\text { (range of options) }\end{array}$ & $\begin{array}{l}\text { Oriented to task or } \\
\text { relations. }\end{array}$ & $\begin{array}{l}\text { Directive towards the } \\
\text { goal. }\end{array}$ & $\begin{array}{c}\text { From the task-oriented } \\
\text { behavior to the } \\
\text { relation-oriented } \\
\text { behaviour. }\end{array}$ \\
\hline $\begin{array}{l}\text { Research base } \\
\text { (number of studies } \\
\text { proving) }\end{array}$ & $\begin{array}{l}\text { Broad, in many } \\
\text { enterprises (military, } \\
\text { education, industry). } \\
\text { Some contradictory } \\
\text { results. }\end{array}$ & $\begin{array}{l}\text { Medium to small. } \\
\text { Usually confirming. }\end{array}$ & $\begin{array}{l}\text { Small, but usually } \\
\text { confirming. }\end{array}$ \\
\hline $\begin{array}{l}\text { Application value for } \\
\text { managers }\end{array}$ & $\begin{array}{l}\text { Medium to small. } \\
\text { Leaders can not be } \\
\text { trained. }\end{array}$ & Medium. & Medium but growing. \\
\hline
\end{tabular}




\section{CONCLUSIONS}

In relation to the need to understand and apply the integration of current management approaches and principles there have been specified three, mainly personal, qualities that contribute significantly to the ability to lead and influence others. They agree with the majority of styles and are particularly compatible with the situational approach:

1. The leader should be aware of the impact of their behavior on those who they manage. Therefore, they should seek to learn more about their actions towards others.

2. An important capability of effective leaders is to be able to organize correctly, to understand themselves, the tasks given to their subordinates and their situation, they must understand the relationship of cause and effect of individual motivation and behavior, as well as group dynamics and group behavior.

3. Every manager must be able to communicate with subordinates. If they lack this ability, they may be unable to influence others.

\section{Ability to organize}

Organization is especially critical for the ability of managers to delegate tasks to individual workers and coordinate their efforts to carry out the work. It requires immense patience with diverse individuals of different skills and abilities to learn new ideas and ways of working.

The crisis manager should have:

- ability to understand the tasks, employing the necessary critical thinking and strategic foresight,

- ability to perform tasks and manage activities and processes that require proactive approach, self-confidence, selfcontrol and flexibility.

The quality of organisation is very important in dealing with corporate crises, so the emergency manager and the team must know exactly:

- how, where and when to do the tasks,

- who has responsibility for which task,
- with whom and in which activities they should cooperate,

- who to manage,

- what are the rights and obligations.

\section{Ability to communicate}

Communication should provide the correct information to other teams' personnel, ie. clearly explain the roles and responsibilities of the individual team members, give them guidance and direction regarding the task. The communication process is an important part of all management processes, especially during crisis solving its importance increases significantly. The crisis manager has the ability to choose a method of communication that will allow him to communicate with each team member.

The most important communication skills of the crisis manager are oral and written communication skills, interpersonal skills, ability to think creatively, analyze objectively, effective decision making, as well as the preparation of strategic and tactical plans.

The preparedness of managers to deal with crises should be given sufficient attention. In this context, it is possible to focus on such tasks as:

- improvement of the ability to perceive signals of crisis,

- practicing the performance of tasks during the crisis,

- improvement of communication skills of crisis managers, speakers, etc..,

- carry out exercises on the skills to formulate factual, clear and comprehensive reports,

- practicing management methods and techniques of communication through the media.

A crisis management team requires both the determination and authoritarianism, and on the other hand, sensitivity and understanding (crisisaffected people can be psychically unstable, passive and euphoric, their behavior may be irrational - examples of evacuation of flooded homes - people refused to leave their homes). It is difficult to work on such conditions, and the crisis manager must have the appropriate skills.

The management team also needs good interpersonal relationships and understanding. 
At its formation, it is important that the members are able to contribute their skills, knowledge and expertise towards the goal. The crisis manager should trust their skills, be willing to take responsibility for their decisions and behave so that other people trust him, follow and support him. He should treat all employees objectively, because a sense of injustice and inequality adversely affects employee motivation.

Similarly, it is also rescue teams that provide assistance to those in need. Often, teams work together during an intervention, which puts greater demands on management and control of persons who are not directly subordinate to the commander (crisis manager). The commander communicates with the crisis affected people, gaining information from bystanders, cooperates with other divisions of the IRS, which places high demands on communication and management skills.

Leading people in rescue services is directed by internal guidance and routine and information flow are strictly set. Even with this approach to leadership, there is some room for the implementation of various elements of management styles. For example, during the time paramedics spend directly at the scene where they often have to create their own system of coordination and activities that are not explicitly included in any of the known styles. In this case, the commander often applies the democratic management style to give the team identity and build united spirit.

The approach to a subordinate outside the incident scene must be equal, fair and balanced. Preferring or rejecting any of the subordinates can later lead to the failure of the intervention.

Using situational approaches in the fire department is one of the possible and effective tools for keeping people effective in stressful situations such as fire incidents. Firefighters are exposed to different environmental factors and proper management style creates conditions for a successful completion of the action and the protection of life and health in emergencies. The nature of activities and intervention characteristics and readiness of individuals requires often the commander's individual attention.

It should be noted that the management of subordinates could be understood in two ways. The first one is no-intervention activity at fire station, where a superior approach can be partially relaxed for tasks often subject to strict compliance with the orders of the commander.

The second area is the intervention action where the manager may relax their approach to a much lesser extent. Despite this fact, the use of these approaches during rescue works is desirable and the individual commanders should adopt it and use it to communicate with their subordinates.

\section{Works Cited}

Buganová, K. (2010). Management of the enterprise in crisis. Economic Crisis sight from interested (p. 5). Žilina: Žilinská univerzita.

Donnelly, J., Gibson, J., \& Ivancevich, J. (1997). Management. Praha: Grada Publishing.

Majtán, M. (2008). Management. Bratislava: Sprint.

Míka, V. (2007). Principles of management for safety managers. Žilina, Žilina, Slovak Republic: University of Žilina. Retrieved from http://fsi.uniza.sk/kkm/publikacie/mika_ma.html

Vel'as, A. (2011). Selection and evaluation of human potential in commercial security in Slovakia. The quality and price of services in the private security: scientific expert workshop with international participation. Žilina: Žilinská univerzita.

This paper has been prepared under the projects VEGA 1/1082/11 and VEGA 1/0743/11 
Hudáková M. Situational approaches to leading people

MEST Journal Vol.1 No.1 pp. 94 - 102

Received for publication: $\quad 14.09 .2012$

Revision received: $\quad 07.12 .2012$

Accepted for publication: $\quad 21.12 .2012$

\section{How to cite this article?}

Style - APA Sixth Edition:

Hudakova, M., \& Svetlik., J. (2013, 01 15). Situational approaches to leading people in the fire service. (Z. Čekerevac, Ed.) MEST Journal, 1(1), 94-101. Retrieved from

www.meste.org/mest/MEST $12013 /$ 10.pdf. doi: 10.12709/mest.01.01.01.10.pdf

Style - Chicago Fifteenth Edition:

Hudakova, Maria, and Jozef Svetlik. "Situational approaches to leading people in the fire service."

Edited by Zoran Čekerevac. MEST Journal (MESTE NGO) 1, no. 1 (01 2013): 94-101.

Style - GOST Name Sort:

Hudakova Maria and Svetlik. Jozef Situational approaches to leading people in the fire service [Journal] = Leading people in the fire service // MEST Journal / ed. Čekerevac Zoran. - Belgrade Toronto : MESTE NGO, 01 15, 2013. - 1 : Vol. 1. - pp. 94-101.

Style - Harvard Anglia:

Hudakova, M. \& Svetlik., J., 2013. Situational approaches to leading people in the fire service. MEST Journal, 15 01, 1(1), pp. 94-101.

Style - ISO 690 Numerical Reference:

Situational approaches to leading people in the fire service. Hudakova, Maria and Svetlik., Jozef. [ed.] Zoran Čekerevac. 1, Belgrade - Toronto : MESTE NGO, 01 15, 2013, MEST Journal, Vol. 1, pp. 94-101. 